\title{
Colonic Laterally Spreading Tumor Diagnosed as an Early Cancer and Treated with Endoscopic Mucosal Resection: A Case Report and Review of Literature
}

\author{
Mohamad Abdelaziz 1,2*, Motaz Sayed ${ }^{2,3}$
}

1. Department of Tropical Medicine and Gastroenterology, University of Sohag, Egypt

2. Mohamad Dossary Hospital, Saudi Arabia

3. Department of Internal Medicine, University of Ein Shams, Egypt

\section{* Corresponding Author:}

Mohamad Abdelrahman Abdelaziz, MD Gastroenterology Department, Mohamad Dossary Hospital, Al Khobar-31952, P.O.Box 335, Kingdom of Saudi Arabia Tel: +966561629905

Fax: +966138950735

Email: mohamedabdulrahman@mdh.com.sa

Received: 17 Sep. 2016

Accepted: 01 Dec. 2016

\section{ABSTRACT}

Laterally spreading tumors (LSTs) are generally defined as superficial lesions $\geq 10 \mathrm{~mm}$ in diameter that typically extend laterally rather than vertically along the colonic wall. Such lesions are now increasingly reported because of increased awareness and the introduction of chromo and magnifying colonoscopy. Although the clinicopathological characteristics and the efficacy of endoscopic management of LSTs have been defined in Japanese cohorts, reports from the Middle East are lacking where surgical resection is the mainstay of treatment. We report a case with an LST about 20 $\mathrm{cm}$ from anal verge removed by endoscopic mucosal resection. After histopathological evaluation of the removed specimen, we categorized the patient as having high risk early colon cancer. The intensive follow-up as an additional treatment strategy was chosen for the patient. This review addresses the management of early carcinoma in colorectal polyp with reference to proper preoperative assessment, treatment selection with special attention to role of biomarkers, the need for additional treatment on the basis of the presence of risk factors and endoscopic follow-up after treatment. KEYWORDS:

Laterally spreading tumor, Endoscopic mucosal resection, Early colorectal cancer, Tumor

Please cite this paper as:

Abdelaziz M, Sayed M. Colonic Laterally Spreading Tumor Diagnosed as an Early Cancer and Treated with Endoscopic Mucosal Resection: A Case Report and Review of Literature. Middle East J Dig Dis 2017;9:49-54. DOI: 10.15171/mejdd.2016.51

INTRODUCTION

By definition laterally spreading tumors (LSTs) are superficial tumors that spread laterally along the colon wall with $\geq 10 \mathrm{~mm}$ diameter. ${ }^{1}$ There are two main types of LSTs: Granular (G-LST) and flat (F-LST) types. ${ }^{2}$ G-LST was subclassified into homogeneous and mixed nodular subtypes. F-LST was subclassified into elevated and pseudodepressed subtypes. ${ }^{3}$ The number of reported LSTs is enormously increasing. The use of dye assisted colonoscopy and/or new imaging techniques increased not only their detection but also determination of their invasion depth. ${ }^{4}$ From Japan, many reports ${ }^{2,5-8}$ showed and established the efficacy of both endoscopic mucosal resection (EMR) and endoscopic submucosal dissection (ESD) in the management of LSTs. Such reports from the Middle East are lacking as surgery is the most established curative treatment. Herein we describe a patient with LST that after discussion with him, we decided to treat him endoscopically using EMR. 


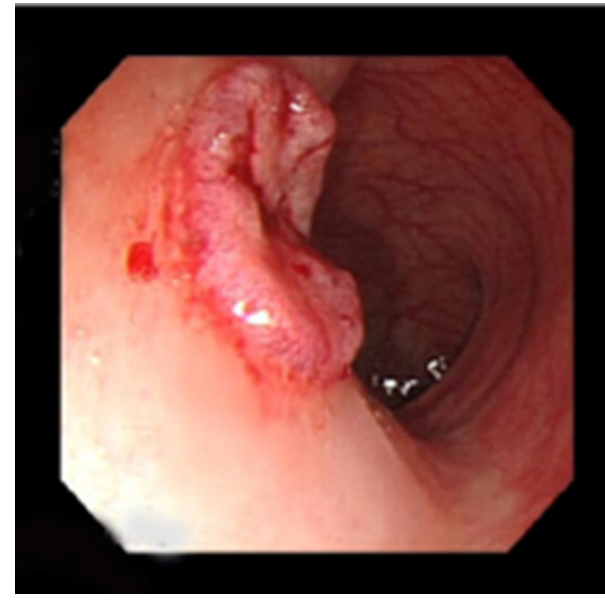

Fig.1: LST of pseudodepressed flat type after lift with saline and adrenaline injection.

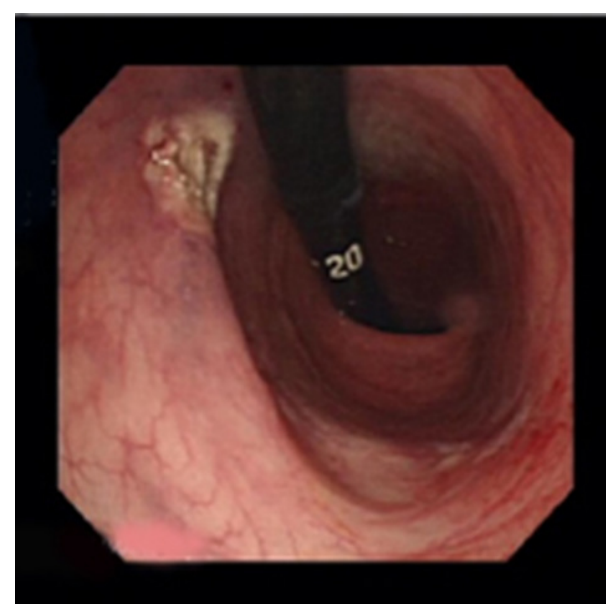

Fig.2: En bloc excision seen with retroflexion of the scope.

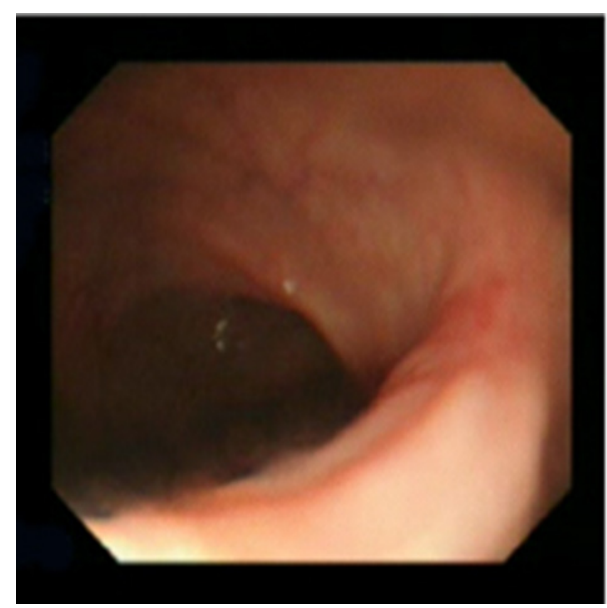

Fig.3: Scar at the site of excision after 3 months.

\section{CASE REPORT}

We report a case of endoscopically treated LST at the Gastroenterology Unit of Mohamad Dossary Hospital, Kingdom of Saudi Arabia in April, 2012. A 40-year-old Indian man presented with a pseudodepressed flat type LST (figure 1), which was about $2 \mathrm{~cm}$ in diameter, located at about $20 \mathrm{~cm}$ from the anal verge with slight central depression (0-IIa+IIc) at colonoscopy (Olympus, CF Q 260 AL, Tokyo, Japan). The patient had complained of lower abdominal pain and bleeding per rectum for 2 months. Abdominal and pelvic computed tomography (CT) showed no hepatic or lymph node metastasis. When the LST was detected, after discussion with the patient about the benefits and risks of endoscopic and surgical approaches, we decided to treat him endoscopically using EMR. The reasons for this decision were: 1) this was the patient's choice, 2) the experience with colonic ESD was, at that time, limited, and 3) this LST showed that the whole lesion could be taken within the polypectomy snare, the anatomical position and extension made it accessible for endoscopic removal, complete symmetrical lift on submucosal injection and no coagulation abnormality was detected. Informed consent was obtained from the patient including the consent for publishing the data.

Endoscopic removal was done by snare EMR (Olympus, SD-210 U-25, Tokyo, Japan) (figure 2) after submucosal injection of about 8-10 cc normal saline and diluted adrenaline $(1 / 20.000)$ to produce submucosal cushion and to test the lifting sign. We used a blended current with power settings at 25 watts. No complications were detected during the post-operative hospital stay. Histopathology report showed an adenomatous lesion with carcinoma that invaded the muscularis mucosa and submucosa down to $\mathrm{sm} 2$. No free lateral or vertical margins were detected. The patient chose the follow up strategy. No recurrence was detected, 3 months after the first colonoscopy (figure 3 ). The patient did not come back for regular follow-up visits. He came back after about 30 months with bleeding per rectum. Colonoscopy revealed a mass at the vicinity of the previous lesion, which was diagnosed as invasive adenocarcinoma and treated surgically. 
We searched PubMed database for publications about colon EMR by using the keywords EMR and colon. Then citation tracking of the relevant publications was done. When we used the same keywords with adding another keyword Middle East, Egypt, Saudi Arabia or Arabic countries, we got no results. So, we present this case report and review the literature for up to date management of colorectal polyps with early cancer.

\section{Management of colorectal polyps with early carcinoma:}

The term early carcinoma refers to carcinoma confined to mucosa or submucosa. ${ }^{9,10}$ This should be gone through the following steps:

A. Proper preoperative assessment for detection of features that suggest any change into malignancy and its invasion depth. These features include the large size, irregularity, ulceration, hardness and broadening of stalk, type 0-IIc, pit pattern type V (non-structural). Also, include LSTs of non-granular type, a big nodule in granular type and/or non-lifting on submucosal injections. ${ }^{11}$

This can be done through:

-The Kudo pit pattern describes the pattern of intestinal crypt openings utilizing dye-assisted magnifying colonoscopy. The polyps are classified from I to $\mathrm{V}$ types. ${ }^{12}$

- Paris classification, through regular colonoscopy examination by which the polyps can be categorized into protruding (0-I), excavated (0-III), or non-protruding, non-excavated (0-II). The protruding class has been subclassified into pedunculated (0-Ip) or sessile (0-1s) lesions. Type 0-II lesions are further divided into 0-IIa (slightly elevated), 0 -IIb (flat), and 0-IIc (slightly depressed) types., ${ }^{9,10}$

- Narrow band imaging (NBI) usually done with magnification. So it is easy to pick neoplastic from nonneoplastic lesions. Also, it helps to determine their depth of invasion. ${ }^{13}$

- Flexible spectral imaging color enhancement (FICE) has an advantage over the NBI as it can be used without magnification. ${ }^{14}$

- Endosonography for rectal (not for colonic) lesions. ${ }^{11}$

- Confocal local endoscopy (CLE) is highly diagnostic in colorectal neoplasms, competing with histopathology in its diagnostic accuracy. ${ }^{15}$

- Non-lifting sign of Uno: ${ }^{16}$ If submucosal injection resulted in non- or poor lifting of the lesion, technical difficulties and more frequent adverse events will hap- pen during its endoscopic removal. ${ }^{17}$ This sign may be due to submucosal invasion or fibrosis that might be induced by biopsy.

B. Treatment selection: Treatment target should be en bloc resection with free lateral and vertical margins. ${ }^{11}$

There are various studies, using different biomarkers, trying to stratify colorectal cancer into indolent or aggressive subtypes aiming at individualized treatment selection. So, surgically fit patients with aggressive tumors are offered radical surgery. Leong and colleagues ${ }^{18}$ quantified gene methylation utilizing bisulphite pyrosequencing in specimens from patients after total mesorectal excision. They constructed models for predicting nodal and distant metastasis and lymphovascular spread with sensitivities of about $91 \%, 85 \%$, and $100 \%$, specificities of about $55 \%, 45 \%$, and $51 \%$, positive predictive values of about $60 \%, 63 \%$, and $100 \%$, and negative predictive values of about $89 \%, 74 \%$ and $91 \%$, respectively.

i. Endoscopic approach: Predicted mucosal cancer or carcinoma with exiguous submucosal invasion and possibility of en bloc resection can be treated endoscopically. ${ }^{19}$

Types of endoscopic approach: either EMR when the lesion is less than $2 \mathrm{~cm}$; Piecemeal EMR when the lesion is more than $2 \mathrm{~cm}$, usually LST of nodular mixed subtype of the granular type with big nodules or parts of type $\mathrm{V}_{1}$ pit pattern; ${ }^{20,21}$ or ESD when the lesion is more than $2 \mathrm{~cm}$ and the en bloc resection cannot be easily achieved with EMR, mucosal lesions with fibrosis, residual lesion after a trial of endoscopic removal. ${ }^{22}$

Outcomes of endoscopic approach: Tanaka and colleagues ${ }^{23}$ reviewed the literature for colorectal EMR and ESD outcomes and found highly variable rates of post-operative bleeding, perforation, en bloc complete endoscopic and histological resections, and post-operative recurrence. These can be due to heterogeneity in the target lesions, level of experience of endoscopists, and the patients' criteria or co-morbidities. Actually, the comparison between EMR and ESD is misplaced because currently each has its unique indications and ESD was found to be an alternative to surgery not to EMR.

ii. Surgical approach: It should be offered to patients for whom complete endoscopic resection cannot be achieved. ${ }^{11} \mathrm{~A}$ detailed discussion is out of the scope of this review. 


\section{Proper histopathological assessment:}

- Depth of invasion: This can be evaluated by the validated descriptive systems (Haggitt classification, ${ }^{24}$ for sessile and pedunculated polyps, Kikuchi classification, ${ }^{25}$ for sessile polyps) or by direct measurement of invasion below the muscularis mucosae (Kitajima and co-workers ${ }^{26}$ ) provided that the polyp has been removed intact and processed correctly. Kikuchi and colleagues ${ }^{25}$ reported the risk of lymph node metastases ranging from $0 \%$ in sm1(submucosa invasion level 1) carcinomas to $14.4 \%$ in sm3 lesions.

- Margin of resection: No consensus definition exists. The presence of cancer at or close to $(<1 \mathrm{~mm})$ the deep resection margin of a resected malignant polyp is associated with a significant risk of residual tumor within the draining lymph nodes or bowel wall. ${ }^{11}$

-Lymphovascular invasion is associated with an increased risk of lymph node involvement in a malignant polyp, although lymphovascular invasion occurring without other adverse features is an unusual finding. ${ }^{11}$

- Cancer differentiation: poor differentiation of cancer in a malignant polyp is an unusual finding but is associated with a high risk of residual disease in the lymph nodes. It is usually associated with other risk factors for residual disease. ${ }^{11}$

\section{Additional treatment:}

i. Immediately after endoscopic resection: It is wise to visually assess the resection site after dye spray or with the use of NBI/FICE). If there is a residual neoplasm, it can be resected with mini snares or with argon plasma coagulation (APC). ${ }^{11}$ Use of APC is still a controversial issue as Moss and co-workers ${ }^{28}$ reported that the tumor size ( $\geq 4 \mathrm{~cm}$ ) and APC use can independently predict recurrence after EMR.

ii. After histopathological assessment: Lesions with the following criteria can be managed either by surgery ${ }^{28}$ or by follow-up strategy: Haggitt level 4, sm1 or sm2 sessile lesions with poor differentiation, lymphovascular invasion, or non-clear resection margins, and sm3 sessile lesions. The follow-up regimen is not well established and is advised to be left to the patient's decision after detailed explanation of benefits and drawbacks of both approaches. ${ }^{11}$ There is no difference in survival between surgical and endoscopic management after a mean follow-up of 25.1 months ${ }^{29}$ High risk early rectal cancer has higher local recurrence risk than first thought.
So, these patients should receive adjuvant chemoradiotherapy, assuming that further surgery is inappropriate. ${ }^{30}$

E. Endoscopic follow-up:

For endoscopically removed malignant polyps, the British Society of Gastroenterology/Association of Coloproctology (BSG/ACP) guidelines recommend surveillance of the excision site by re-scope at 3 months. If there is any doubt about completeness of excision, for example following piecemeal EMR, then a further examination 6 months later is recommended. If there is no recurrence then surveillance reverts to the $\mathrm{BSG} / \mathrm{ACP}$ surveillance guidelines. ${ }^{31}$ In the USA, a 3-month postresection follow-up of the site itself then follow-up colonoscopy at 1,3 , and 5 years postresection is recommended. ${ }^{32}$ Repici and colleagues ${ }^{33}$ recommended 1-3-month follow-up colonoscopy throughout the first 2 years after piecemeal resection of early colorectal cancer. While for en bloc excision, they recommended 3-6-month followup colonoscopy for the first 2 years. This is based on the evidence that with larger and more numerous polyps there is a higher rate of metachronous advanced adenomas. ${ }^{34}$ These variable follow-up schemes are due to different recurrence rates, which may be explained by different individual tumor behavior, studied populations, definitions of complete excision, experience of the operators and the number of patients per center.

\section{CONFLICT OF INTEREST}

The authors declare no conflict of interest related to this work.

\section{REFERENCES}

1. Kudo S. Endoscopic mucosal resection of flat and depressed types of early colorectal cancer. Endoscopy 1993;25:455-61. doi: 10.1055/s-2007-1010367

2. Okamoto T, Tanaka S, Haruma K, Hiraga Y, Kunihiro M, Goishi $\mathrm{H}$, et al. Clinicopathologic evaluation on colorectal laterally spreading tumor (LST). Nihon Shokakibyo Gakkai Zasshi 1996;93:83-9. doi: 10.1016/ S0016-5107(97)80382-3

3. Kudo Se, Lambert R, Allen JI, Fujii H, Fujii T, Kashida $\mathrm{H}$ et al. Nonpolypoid neoplastic lesions of the colorectal mucosa. Gastrointest endosc 2008;68:S347. doi: 10.1016/j.gie.2008.07.052

4. Hurlstone DP, Sanders DS, Cross SS, Adam I, Shorthouse AJ, Brown S. et al. Colonoscopic resection of lateral spreading tumors: a prospective analysis of endoscopic mucosal resection. Gut 2004;53:1334-9. 


\section{doi: 10.1136/gut.2003.036913}

5. Tanaka S, Haruma K, Oka S, Takahashi R, Kunihiro $\mathrm{M}$, Kitadai $\mathrm{Y}$ et al. Clinicopathologic features and endoscopic treatment of superficially spreading colorectal neoplasms larger than $20 \mathrm{~mm}$. Gastrointest Endosc 2001;54:62-6. doi: 10.1067/mge.2001.115729

6. Higaki S, Hashimoto S, Harada K, Nohara H, Saito $\mathrm{Y}$, Gondo $\mathrm{T}$ et al. Long-term follow-up of large flat colorectal tumors resected endoscopically. Endoscopy 2003;35:845-9. doi: 10.1055/s-2003-42622

7. Saito Y, Fujii T, Kondo H, Mukai H, Yokota T, Kozu $\mathrm{T}$ et al. Endoscopic treatment for laterally spreading tumors in the colon. Endoscopy 2001;33:682-6. doi: $10.1055 / \mathrm{s}-2001-16213$

8. Koba I, Yoshida S, Fujii T, Hosokawa K, Park SH, Ohtsu A et al. Diagnostic findings in endoscopic screening of superficial colorectal neoplasia: results from a prospective study. Jpn J Clin Oncol 1998;28:542-5. doi: 10.1093/jjco/28.9.542

9. The Paris endoscopic classification of superficial neoplastic lesions: esophagus, stomach, and colon. Gastrointest Endosc 2003;58:S3-43. doi:10.1016/ S0016-5107(03)02159-X

10. Update on the Paris classification of superficial neoplastic lesions in the digestive tract. Endos $\neg$ copy 2005; 37:570-8. doi: 10.1055/s-2005-861352

11. Williams JG, Pullan RD, Hill J, Horgan PG, Salmo $\mathrm{E}$, Buchanan GN, et al. Management of the malignant colorectal polyp: ACPGBI position statement. Colorectal Dis 2013;15:1-38. doi: 10.1111/ codi.12262. 10.

12. Kudo S, Tamura S, Nakajima T, Yamano H, Kusaka $\mathrm{H}$, Watanabe H. Diagnosis of colorectal tumorous lesions by magnifying endoscopy. Gastrointest Endosc 1996;44:8-14. doi: 10.1016/S0016-5107(96)70222-5

13. Wu L, Li Y, Li Z, Cao Y, Gao F. Diagnostic accuracy of narrow-band imaging for the differentiation of neoplastic from non-neoplastic colorectal polyps: a meta-analysis. Colorectal Dis 2013;15:3-11. doi:10.1111/j.1463-1318.2012.02947.x

14. Yoshida N, Naito Y, Inada Y, Kugai M, Inoue K, Uchiyama K, et al. The detection of surface patterns by flexible spectral imaging color enhancement without magnification for diagnosis of colorectal polyps. Int J Colorectal Dis 2012;27:605-11. doi: 10.1007/ s00384-011-1380-8

15. Su P, Liu Y, Lin S, Xiao K, Chen P, An S, et al. Efficacy of confocal laser endomicroscopy for discriminating colorectal neoplasms from non-neoplasms: a systematic review and meta-analysis. Colorectal Dis 2013;15: e1-12. doi: 10.1111/codi.12033

16. Uno Y, Munakata A. The non-lifting sign of invasive colon cancer. Gastrointest Endosc 1994;40:485-489. doi: 10.1016/S0016-5107(94)70216-0

17. Takeuchi Y, Iishi H, Tanaka S, Saito Y, Ikematsu H,
Kudo SE, et al. Factors associated with technical difficulties and adverse events of colorectal endoscopic submucosal dissection: retrospective exploratory factor analysis of a multicenter prospective cohort. Int J Colorectal Dis 2014;29:1275-84. doi: 10.1007/ s00384-014-1947-2

18. Leong KJ, Beggs A, James J, Morton DG, Matthews GM, Bach SP. Biomarker-based treatment selection in early-stage rectal cancer to promote organ preservation. Br J Surg 2014;101:1299-309. doi: 10.1002/ bjs. 9571

19. Watanabe T, Itabashi M, Shimada Y, Tanaka S, Ito Y, Ajioka Y, et al. Japanese Society for Cancer of the Colon and Rectum (JSCCR) guidelines 2010 for the treatment of colorectal cancer. Int J Clin Oncol 2012;17:1-29. doi: 10.1007/s10147-011-0315-2

20. Uraoka T, Saito Y, Matsuda T, Ikehara H, Gotoda T, Saito D, et al. Endoscopic indications for endoscopic mucosal resection of laterally spreading tumors in the colorectum. Gut 2006;55:1592-7. doi: 10.1136/ gut.2005.087452

21. Oka S, Tanaka S, Kanao H, Oba S, Chayama K. Therapeutic strategy for colorectal laterally spreading tumor. Dig Endosc 2009;21:S43-6. doi: 10.1111/j.14431661.2009.00869.x

22. Tanaka S, Terasaki M, Kanao H, Oka S, Chayama K. Current status and future perspectives of endoscopic submucosal dissection for colorectal tumors. Dig Endosc 2012;24:73-9. doi: 10.1111/j.1443-1661.2012.01252.x

23. Tanaka S, Terasaki M, Hayashi N, Oka S, Chayama $\mathrm{K}$. Warning for unprincipled colorectal endoscopic submucosal dissection: accurate diagnosis and reasonable treatment strategy. Dig Endosc 2013;25:1076. doi:10.1111/den.12016

24. Haggitt RC, Glotzbach RE, Soffer EE, Wruble LD. Prognostic factors in colorectal carcinomas arising in adenomas: implications for lesions removed by endoscopic polypectomy. Gastroenterology 1985;89:32836. doi: 10.1016/0016-5085(85)90333-6

25. Kikuchi R, Takano M, Takagi K, Fujimoto N, Nozaki R, Fujiyoshi T, et al. Management of early invasive colorectal cancer. Risk of recurrence and clinical guidelines. Dis Colon Rectum 1995;38:1286-95. doi: 10.1007/BF02049154

26. Kitajima K, Fujimori T, Fujii S, Takeda J, Ohkura Y, Kawamata H, et al. Correlations between lymph node metastasis and depth of submucosal invasion in submucosal invasive colorectal carcinoma: a Japanese collaborative study. $J$ Gastroenterol 2004;39:534-43. doi: 10.1007/s00535-004-1339-4

27. Moss A, Bourke MJ, Williams SJ, Hourigan LF, Brown G, Tam W, et al. Endoscopic mucosal resection outcomes and prediction of submucosal cancer from advanced colonic mucosal neoplasia. Gastroenterology 2011;140:1909-18. doi: 10.1053/j.gastro.2011.02.062 
28. Nascimbeni R, Burgart LJ, Nivatvongs S, Larson DR. Risk of lymph node metastasis in T1 carcinoma of the colon and rectum. Dis Colon Rectum 2002;45:200-6. doi: 10.1007/s10350-004-6147-7

29. Gill MD, Rutter MD, Holtham SJ. Management and short-term outcome of malignant colorectal polyps in the north of England. Colorectal Dis 2013;15:16976. doi: $10.1111 /$ j.1463-1318.2012.03130.x

30. Wagman RT, Minsky BD. Conservative management of rectal cancer with local excision and adjuvant therapy. Oncology (Williston Park) 2001;15: 513-9, 524.

31. Cairns SR, Scholefield JH, Steele RJ, Dunlop MG, Thomas HJ, Evans GD, et al. Guidelines for colorectal cancer screening and surveillance in moderate and high risk groups (update from 2002). Gut 2010;59: 666-89. doi: 10.1136/gut.2009.179804

32. Rex DK, Kahi CJ, Levin B, Smith RA, Bond JH, Brooks D, et al. Guidelines for colonoscopy surveillance after cancer resection: a consensus update by the American Cancer Society and the US Multi-Society Task Force on Colorectal Cancer. Gastroenterology 2006;130:1865-71. doi: 10.1053/j.gastro.2006.03.013

33. RepiciA, Pellicano R, Strangio G, Danese S, Fagoonee $\mathrm{S}$, Malesci A. Endoscopic mucosal resection for early colorectal neoplasia: pathologic basis, procedures, and outcomes. Dis Colon Rectum 2009;52:1502-15. doi: 10.1136/gutjnl-2015-309861.891.

34. Martinez ME, Baron JA, Lieberman DA, Schatzkin A, Lanza E, Winawer SJ, et al. A pooled analysis of advanced colorectal neoplasia diagnoses after colonoscopic polypectomy. Gastroenterology 2009;136:83241. doi: 10.1053/j.gastro.2008.12.007. 